\title{
Preliminary studies on differ ent extracts of some honey bee products
}

\author{
Rajinder K aur, Preeti K alia*, Neelima R. K umar and K usum Harjai ${ }^{1}$
}

Department of Zoology, Panjab University, Chandigarh, INDIA

'Department of Microbiology, Chandigarh, INDIA

*Corresponding author. E-mail: preeti.kalia84@ gmail.com

Received: August 17, 2013; Revised received:September 18, 2013; Accepted: September 25, 2013

Abstract: The aim of present study was to compare the phytochemical composition of different extracts of bee pollen, propolis and honey and to analyse the best solvent for maximum phytochemicals extraction. These preliminary studies are significant in locating the pharmacological bioactive compounds in different extracts of bee products. The tests showed greater number of constituents present in bee pollen and propolis as compared to honey. The concentration of these bioactive constituents was greater in ethanolic extract of propolis and water extract of bee pollen and honey. Ethanolic extract of propolis showed higher concentration of tannins and glycosides. Bee pollen had more concentration of saponins, flavonoids and proteins in water extract. Reducing sugars and carbohydrates were present in larger amount in water extract of honey. These studies will be useful to select the best solvent for honey, pollen and propolis for various research purposes.

Keywords: Honey, Phytochemical, Pollen, Propolis

\section{INTRODUCTION}

Phytochemicals are non-nutritive plant chemicals that have health-promoting properties. They are natural bioactive compounds that can protect man from several diseases and help in risk reduction for a variety of chronic conditions Russo, 2007). In recent years, phytochemicals, previously with unknown pharmacological activities, have been extensively investigated as a source of medicinal agents (Krishnaraju et al., 2005). Since time immemorial, man has used various parts of plants in the treatment and prevention of various ailments (Tanaka et al., 2002).

Bee pollen is collected by worker honey bees from flowering plants and stored in their hives. The bees only select and collect those pollens which are rich in nutrition (Szczesna, 2006 ). Pollen helps to regulate and stimulate metabolism in humans by providing certain missing factors that other foods lack and neutralizes the catabolic effects of various toxins and synthetic drugs thereby producing healthier cells, improved health and a longer life-span (Sramkova et al., 2013).

Propolis is referred to as bee glue because it is used for construction and to seal the cracks in the bee hive. It is the sap or resin collected from plants by honey bees and combined with their own enzymes.
Propolis has some medicinal properties and is known for its antimicrobial, antitumor and antioxidant activities. It is also used in cosmetics. A honey bee collects nectar from plants and mixes it with the enzymes to convert it into honey. Honey's ability to heal wounds and treat infections is well established. It is also known for its antioxidant, antibiotic and antiviral capabilities (Ferreira et al., 2009).The present study was designed to understand the difference in the constituents present in ethanolic and water extracts of bee pollen, propolis and honey in relation to their medicinal capabilities.

\section{MATERIALS AND METHODS}

Collection of bee pollen, propolis and honey: These bee products of Apis mellifera were collected from Langstroth hive placed in the field of Brassica campestris. Bee pollen was collected by installing a pollen trap at the entrance of hive. Propolis was collected by scrapping it from the frames with the help of hive tool. Honey was collected by tilting the hive comb which was filled with honey.

Preparation of extract of differ ent bee products: Water and ethanol were used as solvent for the preparation of extracts. Extract of bee pollen was prepared by following the method of Nagai et al. (2004) with slight modification. $3 \mathrm{~g}$ of fresh bee pollen was suspended and extracted by shaking with 10 volumes of solvent at $20 \mathrm{p} \mathrm{C}$ for 1 day and the extract was centrifuged at $5000 \mathrm{rpm}$ for $1 \mathrm{~h}$. The ISSN : 0974-9411 (Print), $2231-5209$ (Online) All Rights Reserved ๔ Applied and Natural Science Foundation www.ansfoundation.org 
supernatant was collected, filled up to $30 \mathrm{ml}$ with solvent. Extracts of propolis was prepared by following the method of Kumar et al. (2008). The sample (10 g) was cut into small pieces, ground and subsequent solvent extraction was done using ethanol and water. The volume was made to $40 \mathrm{ml}$ and it was kept for 5 days with occasional shaking. It was filtered through a Whatman No. 41 filter paper and then dried. Extracts of honey was prepared by the method of Mohapatra et al. (2011) with suitable modification. $10 \mathrm{~g}$ raw honey was taken in test tube and $25 \mathrm{ml}$ of solvent (ethanol and water) was added. Later, the solutions were mixed with constant shaking and centrifuged at $3000 \mathrm{rpm}$ for $10 \mathrm{~min}$ at $25^{\circ} \mathrm{C}$. The supernatants were collected and transferred to stopper test tubes for phytochemical analysis.

Phytochemical evaluation: Extracts of different bee products were subjected to qualitative chemical analyses to detect the presence of various phytoconstituents (Misra et al., 2011, Vijayalakshmi et al., 2012).

\section{RESULTS AND DISCUSSION}

Plants are the primary source of supply of many important drugs. Since there are so many of these naturally occurring substances of plant origin, it is obvious that the plant kingdom offers a better opportunity of providing useful medicinal compounds for the treatment of various diseases. The phytochemical research based on ethnopharmacological information is generally considered an effective approach in the discovery of new anti-infective agents from higher plants (Duraipandiya et al., 2006).
Therefore, illuminating the phytochemical nature of bioactive components of bee products makes space for synthetic modifications for better pharmacokinetic profiles. Isolation of medicinally important compounds from bee products is depends on the solvent that is used for the extraction. Each solvent used in the extraction procedure had varied concentration of different phytochemical constituents. The recovery of chemical components was best in case of ethanol (Kalia et al 2013) Ethanolic extract of propolis showed greater amount of tannins and glycosides whose presence favours the antibacterial and antioxidative properties of Propolis (Banskota et al, 2001). Water extract of bee pollen had maximum amount of saponins, flavonoids (Kaur et al , 2013). Tannins, saponins, alkaloid, phlobatannins, flavonoid and anthraquinone were absent in honey extract. The phytochemicals detected have previously been shown to exhibit biological activity, such as antibacterial, antitumour and antihelmintic activity (Harborne, 1973). Of the three products viz. pollen, propolis and honey tested during the investigating, it was observed that ethanolic extract of propolis and water extract of bee pollen and honey were best on the basis of the recovery of chemical constituents (Table 1).

\section{Conclusion}

The study revealed that the maximum constituents were extracted from bee pollen and honey with water as a solvent, from propolis with ethanol. These studies can be valuable for research and drug development in the field of pharmacy.

Table 1. Results of phytochemical analysis of water and ethanolic extract of bee products.

\begin{tabular}{|c|c|c|c|c|c|c|c|}
\hline \multirow[t]{2}{*}{ S.No } & \multirow[t]{2}{*}{ T ests } & \multicolumn{2}{|c|}{ Propolis } & \multicolumn{2}{|c|}{ Pollen } & \multicolumn{2}{|c|}{ H oney } \\
\hline & & Water & Ethanol & W ater & E thanol & Water & Ethanol \\
\hline 1 & Tannins & + & +++ & ++ & ++ & - & - \\
\hline 2 & Saponins & + & + & ++ & + & + & - \\
\hline 3 & Carbohydrates & + & + & + & ++ & +++ & ++ \\
\hline 4 & Alkaloids & + & ++ & ++ & + & - & - \\
\hline 5 & Resins & + & +++ & ++ & +++ & + & + \\
\hline 6 & Phlobatannins & + & + & + & - & - & - \\
\hline 7 & Flavonoids & + & ++ & +++ & ++ & - & - \\
\hline 8 & Carbonyl & + & + & + & ++ & +++ & ++ \\
\hline 9 & Anthraquinones & + & + & ++ & - & - & - \\
\hline 10 & Coumarins & + & +++ & +++ & ++ & + & + \\
\hline 11 & Reducing Sugars & + & + & + & ++ & +++ & ++ \\
\hline 12 & Quinones & + & +++ & +++ & ++ & ++ & ++ \\
\hline 13 & Glycosides & + & +++ & ++ & ++ & + & + \\
\hline 14 & Terpenoids & + & +++ & +++ & + & ++ & ++ \\
\hline 15 & Proteins & + & ++ & +++ & +++ & + & + \\
\hline 16 & Steroids & - & + & +++ & ++ & +++ & +++ \\
\hline
\end{tabular}

$+=$ slightly present,$++=$ Moderate,$+++=$ Abundant, $-=$ Absent 


\section{ACKNOWLEDGEMENTS}

The authors would like to thank University Grant Commission, New Delhi and Department of Science and Technology for their assistance at various stages of this research work through Rajiv Gandhi National Fellowship, INSPIRE fellowship and the PURSE grant.

\section{REFERENCES}

Banskota, A.H., Tezuka, Y., Adnyana, I.K., Ishii, E., Midorikawa, K., Matsushige, K. and Kadota, S. (2001). Hepatoprotective and anti-helicobacter pyroli activities of constituents from Brazilian Propolis. Phytomedicine, 8: 1623.

Duraipandiyan, V., Ayyanar, M. and Ignacimuthu, S. (2006). Antimicrobial activity of some ethnomedical plants used by Paliyar tribe from Tamil Nadu, India. B M C C omplementary and Alternative M edicine, 6: 35 .

Ferreira, I.C.F.R., Aires, E., Barreira J. C. M., Estervinho, L.M (2009). Antioxidant activity of Portuguese honey samples: Different contributions of the entire honey and phenolic extract. F ood C hemistry, 114: 1438-1443.

Harborne , J.B. (1973). Phytochemical Methods, $3^{\text {th }}$ Edn, Chapman and Hall Ltd., London. pp.135-203.

Kalia, P., Kumar, R. K. and Harjai, K. (2013). Phytochemical screening and antibacterial activity of different extracts of Propolis. International J ournal of Pharmaceutical and Biological Research, 3:219-222.

Kaur, R., Kumar, N.K. and Harjai, K. (2013). Phytochemical analysis of different extracts of bee pollen. International J ournal of Pharmaceutical and Biological Research, 4: 6568.

Krishnaraju, A. V., Rao, T. V. N. and Sundararaju, D. (2005) Assessment of bioactivity of Indian medicinal plants using Brine shrimp (Artemia salina) lethality assay. Int. J . Appl.
Sci. Eng., 2: 125-134.

Kumar, N., Ahmad, M.K.K., Dang, R. and Husain, A. (2008). Antioxidant and antimicrobial activity of Propolis from Tamil Nadu zone. J ournal of M edicinal Plants Research, 2 (12): 361-364.

Misra, C. S., Pratyush, K., Dev, M. S. L., James, J., Veettil, A. K. T. and Thankamani, V. (2011). A comparative study on phytochemical screening and antibacterial activity on root of Alstonia scholaris with the roots, leaves and stem bark. Int. J. Res Phytochem. Pharmacol., 1(2): 77-82.

Mohapatra, D.P.,Thakur, V. and Brar, S.K. (2011). Antibacterial efficacy of raw and processed honey. Biotechnology Research International, 1-6.

Nagai,T., Nagashima, T., Myoda, T. and Inoue, R. (2004). Preparation and functional properties of extracts from bee bread. Nahrung/F ood, 48 (3): 226 - 229.

Russo, G.L. (2007). Ins and out of dietary phytochemicals in cancer chemoprevention. Biochemical Pharmacology, 74: 533-544.

Sramkova, K.F., Nozkova, J., Kaèániová, M., Máriássyová, M., Rovná, K. and Strièík, M. (2013). Antioxidant and antimicrobial properties of monofloral bee pollen. J . Environ. Sci. Health. B., 48:133-8.

Szczêsna, T. (2006). Protein content and amino acid composition of bee collected pollen from selected botanical origins. J . of A pi. Sci., 50: 81-90.

Tanaka, H., Sato, M. and Fujiwara, S. (2002). Antibacterial activity of isoflavonoids isolated from Erythrina variegata against methicillin resistant Staphylococcus aureus. Lett. Appl. Microbiol., 35: 494- 498.

Vijayalakshmi, R. and Ravindhran, R. (2012). Preliminary comparative phytochemical screening of root extracts of Diospyrus ferrea (Wild.) Bakh and Aerva lanata (L.) Juss. Ex Schulte Asian J o urnal of Plant Science and Research, 2 (5): 581-587. 